\title{
Maximizing potential: A school-based conception of psychosocial development
}

\author{
Tracy L. Cross \\ College of William and Mary, tlcross@wm.edu \\ Jennifer Riedl Cross \\ College of William and Mary, jrcross@wm.edu
}

Follow this and additional works at: https://scholarworks.wm.edu/educationpubs

Part of the Gifted Education Commons

\section{Recommended Citation}

Cross, Tracy L. and Cross, Jennifer Riedl, Maximizing potential: A school-based conception of psychosocial development (2017). High Ability Studies, 28(1), 43-58.

https://doi.org/10.1080/13598139.2017.1292896

This Article is brought to you for free and open access by the School of Education at W\&M ScholarWorks. It has been accepted for inclusion in School of Education Articles by an authorized administrator of W\&M ScholarWorks. For more information, please contact scholarworks@wm.edu. 
Running Head: SCHOOL-BASED CONCEPTION OF PSYCHOSOCIAL DEVELOPMENT

Maximizing Potential: A School-Based Conception of Psychosocial Development

\author{
Tracy L. Cross \\ Jennifer Riedl Cross \\ College of William \& Mary
}

Final version accepted for publication

Cross, T. L., \& Cross, J. R. (2017). Maximizing potential: A school-based conception of psychosocial development. High Ability Studies, 28, 43-58. DOI:

$10.1080 / 13598139.2017 .1292896$ 


\begin{abstract}
Optimal talent development can only occur when high ability students are willing to take opportunities for growth in a domain and are able to persist when presented with challenges that accompany performance or production at the highest levels. This paper proposes the use of Erikson's theory of psychosocial development to provide a framework through which schools can pursue a parallel path of psychosocial supports to reinforce the development of talent in any domain. Ego strength can be fortified by an active program of professional development, curricula, and research based on Erikson's psychosocial stage theory. In addition to the age-based components, ego strength can be promoted by activities that support the essential strengths of hope, will, purpose, skill, fidelity, and love.
\end{abstract}




\section{Maximizing Potential: A School-Based Conception of Psychosocial Development}

What has to happen for a newborn baby to one day become an eminent scientist, athlete or artist? Is it fate or biologically predetermined? Will 10,000 hours of practice make us experts? If so, who will spend that much of his or her time practicing? Even among the most capable of students, exceptional talent must be developed through practice and education. Teaching and learning are complex processes with myriad variables that can affect their success. Beyond the relatively simple act of presenting information and receiving it are hundreds, maybe thousands of potential obstructions to learning. Some of these obstructions are outside the learner, but some are from within. In addition to supporting the development of skills, any talent development agenda must consider the psychological and social variables associated with the learning process. In this paper, we propose the use of a theoretical framework for addressing the psychological and social aspects of talent development.

Discovering increasingly more effective approaches to help students learn has been a primary goal of the field of education since day one. In the past century, we have experimented with methods as diverse as memorization, recitation, cooperative learning, pull-out programming, and special schools. These various approaches have been informed at different times by behaviorism, Gestalt psychology, cognitive psychology, constructivism, and recently, neuropsychological research. In addition, there has arisen a widespread commitment to schools being environments of inclusion, rather than exclusion. Now, more than ever before, our public schools are made up of students from varied backgrounds, abilities, interests, socio-economic status, gender, and ethnicity.

Creating approaches to teaching that can maximize the learning of all students has become a much more complicated task than 150 years ago. Gifted education has had to adapt to 
many of these changes and, in so doing, has been through major changes of its own. For example, modern gifted education emerged with Lewis Terman in the early 1900's with an intelligence quotient conception of giftedness that dominated our thinking for decades. Later the Marland (1972) definition, Renzulli’s (1978) three-ring conception, Gardner's (1983) multiple intelligences, Sternberg's (1986) triarchic theory, Gagné's (1995) Differentiated Model of Giftedness and Talent (DMGT) combined to greatly evolve our thinking of giftedness. In 1985, Bloom's book, Developing Talent in Young People, introduced a way of thinking about giftedness that has been gaining ground ever since. Regardless of the paradigm driving educational efforts (Ambrose, VanTassel-Baska, Coleman, \& Cross, 2010; Dai \& Chen, 2013), however, the goal of the field has been to maximize potential (J. Cross, Cross \& Finch, 2005), with varying levels of interest in the psychological correlates.

According to Cross and Coleman's (2005) school-based conception of giftedness, giftedness is developed capacity in a specific talent domain. These capacities will only be maximally developed in contexts that support learning and practice in those domains and in interaction with "traits of the individual student, such as motivation and perseverance" (p. 62). These individual traits are of particular concern to psychologists. In their mega-model of talent development, Subotnik, Olszewski-Kubilius, and Worrell (2011) specify the contexts required for talent development, with a special emphasis on the individual. Not only must contexts provide opportunity for talent development, but individuals must take these opportunities and apply themselves to achieve success. Schools that offer advanced classes to students who are not motivated to participate or who quit at the first hint of failure will not be successful in developing students' capacities. Research interest in these psychosocial aspects of learning among gifted students has been piecemeal and scant. Attention to the challenges of perfectionism, 
multipotentiality, implicit theories, social comparison, personality, and so forth has been overshadowed by an emphasis on such topics as creativity, teaching strategies, and identification methods (Cross, Cross \& Spike, 2001) Rather than using a cohesive framework to guide research and practice, the field of gifted education resembles a lemming model, haphazardly following interest or popular opinion (e.g., self-concept, implicit theory, "grit"; Ambrose et al., 2010).

Highly talented children can get caught in myriad traps that will keep them from achieving their potential. Despite evidence to the contrary, some capable students will convince themselves they are not so able or they will have difficulty choosing the domain to pursue or they will simply be unmotivated in the domain. Top performers - or those who could be - may also face intense social challenges, with peers who make fun of their abilities or who entice them to socialize rather than work. Our minds are constantly balancing individual wants with perceptions of others and beliefs about their prescriptions for us. We are psychosocial creatures. Clearly, a significant component of talent development is psychosocial, but this component has not been the focus of a targeted, elaborated agenda. To encourage the creation of such an agenda, this paper will, first, describe the applicable foundation of Erikson's (1961, 1963, 1968) psychosocial development theory. It will also describe how his theory can be applied in schools to support talent development among students with exceptional abilities. As specialists in gifted education, it is easy to fall into the trap of assuming that everything about students with gifts and talents is unique. To do these students justice, however, it is imperative that their commonalities be appropriately addressed, not only their uniquenesses. A framework that considers both will be most effective in maximizing their potential.

\section{Psychosocial Development in School}


Schools have access to students for only a portion of their development. For most students, school's influence can only start at pre-Kindergarten and will end after about 14 years. In the US, schools are required to teach students for about 1,000 hours each year (Hull \& Newport, 2011), leaving nearly 5,000 hours of awake time outside of school. Clearly, most psychosocial development is happening outside of schools. While students are in school, however, there is no question they are receiving psychosocial instruction. They interact with peers and adults, are presented with models of adult productivity, and learn what is valued by peers and adults in their communities. All this is done without planning for their successful development. Although most of their psychosocial development will occur outside of school, to achieve the goal of maximized talent development, schools should have a plan based on a sound psychological foundation.

\section{Finding Clues to Psychosocial Support in the History of Psychology}

In life and in the development of talent, certain characteristics are particularly adaptive. The child who is willing to take on new challenges and is not afraid of failure, who works diligently and perseveres, who is a good team player or comfortable superstar, who is confident and self-effacing, who is helpful and willing to seek help - the list can go on and on of characteristics that can lead to individual success. One thing these characteristics have in common is their locus within the child, not as inborn characteristics, but as mindsets and dispositions that arise from thinking.

There is a long history in psychology of attempting to explain the thinking associated with psychological adjustment. In 1923, Freud described the mind as made up of three components. The $i d$ is the libidinous, pleasure-seeker that derives from our primitive, animal nature. The superego is the conscience that attempts to enforce moral standards, governing the id 
in its attempts to act on its instincts. The ego serves as the partially conscious, partially unconscious regulator between these two opposing forces, the realistic negotiator that keeps them in check. This conception of the mind has been elaborated on and modified by Freud's intellectual descendants (Burston, 2007; Hamlyn, 2007). The health of the ego is at the center of psychotherapeutic interventions. The ego in this sense differs from the popular conception of one's self-importance or self-esteem. Ego in this sense is a vital component of positive mental health, deserving, even requiring, attention in any program of psychosocial support. Many approaches to resolving mental distress, from mild to severe, are outgrowths of Freudian psychology: psychodynamic, cognitive behavioral therapy, and humanistic and integrative are a few of the broad applications of psychotherapy descended from his original theory (Hobbes, 2007). The purpose of these various approaches is to "help people of all ages live happier, healthier and more productive lives” (American Psychological Association, 2016, para. 3).

Psychoanalysis attempted to uncover a person's history, assuming that distress in the adult resulted from sexual desires and conflicts in the child's relationship with the mother and father. Freud proposed a psychosexual theory of development, outlining the stages through which a child passes successfully or unsuccessfully. His theory of development ended with puberty, at which time a child has become a sexually functioning adult. Psychological problems in adulthood (e.g., hysteria) could be resolved by examining their roots in early development (Hobbes, 2007) through psychoanalysis. While groundbreaking and enormously influential, Freud's theory left much to be desired in explaining phenomena such as the mindsets and dispositions of interest in talent development. For that we look to one of Freud's "disciples" (Roazen, 1976), Erik Erikson.

\section{Erikson's Psychosocial Theory of Development}


In developmental psychology, perhaps the most influential post-Freudian psychologist is Erik Erikson, architect of the psychosocial theory of development. Critical to his later thinking, Erikson's training was not directly under Freud, but his daughter, Anna, and her colleagues, who were ego psychologists (Burston, 2007). They placed much greater emphasis on the importance of the ego than did Freud, downplaying the conflict between the id and superego. From Freud's psychosexual stages, biology, and his own observational studies, Erikson proposed his own psychosocial theory of development.

In his theory, Erikson acknowledged the significance of childhood history, as did Freud, but he also acknowledged the importance of family members, peers, and society in a person's development. Erikson's psychosocial theory expanded the study of development to include the influence of those in a child's "radius of significant relations" (1982, p. 31). Erikson developed his theory to explain psychological "disturbance" among adults. In the histories of his patients, he could see parallels with his observations of children (Erikson, 1950/1963). The repressed or inhibited adult may have been thwarted in childhood efforts to act of his or her own volition during the preschool or early elementary years. The deeply depressed adult may be unable to trust others because of neglect as an infant. The thwarting of initiative and the neglect in these examples were brought about by individuals in the child's life - people within her or his radius of significant relations. The healing process of psychotherapy could only proceed when these foundations were uncovered.

Erikson proposed a pathway for psychoanalysts to consider in treating unhealthy patients and, in the process, offered a means of creating psychologically healthy adults. With its focus on the academic development of high ability students, our field has neglected this pathway to psychosocial health. By better understanding Erikson's powerful theory, we can integrate its 
principles into a planned program of talent development. Educators of the gifted can take important lessons from the following primer, by considering the psychosocial development of their young charges with exceptional abilities. There is no evidence, as yet, that children with gifts and talents proceed through Erikson's stages at a different pace than that of all other children.

Psychosocial crises. Although he never specified ages at which his proposed stages occur, Erikson borrowed loosely from Freud's psychosexual theory the general ages when crises reach the "stage of ascendancy" (1961, p. 153). Different cultures and different family situations allow different timeframes for each stage (Erikson, 1950/1963). When the person is psychologically ready and her or his environment provides the necessary stimulus, a crisis will occur, not in the sense of a tragedy or danger, but in the sense that a tension between the person and his or her environment must be resolved. Strength and vulnerability of both the individual and the environment interact in this crisis resolution (Erikson, 1950/1980). Successful resolution is what Erikson called a "favorable ratio" (1950/1963, p. 271), not an "achievement" of one or the other extremity of the crisis. Although each crisis occurs at a specified time, the tensions between the individual and environment that stimulate the crises may resurface, causing a need for re-examination of beliefs developed at an earlier stage in life (Newman \& Newman, 1995). Positive progress through the crises results in ego strength (Erikson, 1961), which is also the desirable outcome of psychotherapy. Each crisis has its own resulting virtue or essential strength (Erikson, 1961). Erikson proposed crises faced by humans throughout life, into old age, but we focus only on those relevant for school-aged children, adolescents and college-aged young adults.

Developing hope. Infancy is the time when we all learn to hope. Although the infant seems to be the epitome of vulnerability, he or she survives, not alone, but in concert with those 
around him. In a succinct description of social interdependence, Erikson (1961) writes

Defenceless as babies are, there are mothers at their command, families to protect the mothers, societies to support the structure of families, and traditions to give a cultural continuity to systems of tending and training. (p. 151)

The mother who responds to her infant's cry with nurturance supports the development of hopefulness that one's needs will be taken care of. From the psychosocial crisis of Basic Trust versus Basic Mistrust, infants learn they will be cared for or not, in the case of the child who is neglected. Childcare differs in different cultures, such that allowing an infant to cry may be acceptable. It is not a quantity of food or love that leads a child to be trusting, but the quality of care (Erikson,1950/1980). A mother who is assured in her care, with the confidence that comes from knowing what is traditionally accepted in one's culture, provides the continuity and "sameness" a child needs to successfully navigate this important stage, with the hope that comes from knowing sometimes the outside world can be trusted and sometimes it cannot.

Developing hope in gifted students. Without research to the contrary, we can assume that infantile experiences leading to trust or mistrust are equally likely to occur among gifted and nongifted children. These early experiences create a strong or shaky foundation for the relationships a gifted child has opportunities to build in school. Relationships with teachers, coaches, and peers are influenced by a gifted student's ratio of trust and mistrust, developed from early experiences that schools cannot affect. Ameliorative exercises can help a gifted student at any age find a favorable ratio. Consistency in the classroom, teachers who are responsive and warm (Hamre \& Piante, 2001), and who care for all students will foster a sense of trust. The overly trusting gifted child who holds a hand up with a question or answer and never gets called on may come to assume those questions or answers were not valuable. An untrusting gifted child 
in the same situation may come to dismiss the teacher and school as a place he or she does not belong. Helping students learn how to recognize supporters and non-supporters in their own environment will encourage a healthy balance between trust and mistrust. Such lessons must come with advice for self-advocacy and strategies for gaining support from others.

Developing willpower. As the infant becomes a toddler, hoping for someone to manage his or her needs becomes insufficient. The exercise of will is an essential development from the second crisis of Autonomy versus Shame and Doubt. At this age, children are more able to move, to grasp, to bite, to run. It is critical for them to develop a sense of autonomy, to know they can choose to act on these new powers they possess. However, they must learn when they can not do these things they may want to do. "Foreign overcontrol" (Erikson, 1950/1980, p. 228) - being thwarted in their desire for autonomy by others, such as parents or siblings, who keep them from doing what they want to do - can strip them of self-assurance and create doubt in their ability to act on their own. Willpower comes from a favorable ratio between these two extremes.

Developing willpower in gifted students. Autonomy-supportive parenting and teaching models are based on research that indicates the importance of helping students find the balance between doing what they want to do and learning to submit to the control of others (Baumrind, 1966, 1991; Stefanou, Perencevich, DiCintio, \& Turner, 2004). Gifted children who arrive in school with a tendency to doubt their ability to take action will not achieve their maximum potential without support. They may need to be drawn into new activities and encouraged to make meaningful choices as a means of developing their sense of control. At the other extreme is a child who has been granted too much autonomy, one who resists all efforts at control, even when that resistance is against one's own best interests. The gifted child who demands to act solely on her or his wishes will miss many opportunities, including those for talent development. 
Teachers who allow students to pursue topics of interest support students' autonomy. A highly prescribed curriculum may not allow adequate autonomy for gifted students, even in a homogeneous gifted class. At the same time, some control over students is necessary to maintain an atmosphere where all students can learn. Expecting "self-regulation" in a boring classroom will lead to an unfavorable ratio on the side of shame and doubt. Exploration of a talent domain must be driven by the individual. Without the belief that one can act (within reason) on one's wants and desires, a gifted student cannot achieve his or her potential.

Developing purpose. From hoping to acting willfully, the child at preschool-age is capable of creating organized plans for action. The essential strength that develops is a sense of purpose. The crisis at this age is Initiative versus Guilt. From about ages 3 to 5, children can imagine all sorts of possibilities, including actions they would like to carry out, some with the help of others. Erikson (1950/1995) considered this an important stage for the building of society, because "the child is at no time more ready to learn quickly and avidly, to become bigger in the sense of sharing obligation and performance, than during this period of his development. He is eager and able to make things cooperatively, to combine with other children for the purpose of constructing and planning, and he is willing to profit from teachers and to emulate ideal prototypes." (p. 232). Play allows children to imagine other realities, including adult identities. When the child is allowed to dream and make some of those dreams a reality, she can develop confidence in her own initiative. Such initiative may be struck down, either by other people who have different ideas for one's behavior or by an inability to accomplish what can be imagined. Such failures can lead to frustration, but also guilt that they imagined something that could not be accomplished without negatively affecting or offending others or resulting in punishment (imposed by others or themselves). For a healthy sense of purpose, 
children need opportunities to successfully pursue their initiative, but also should have a sense of realistic limits. They simply cannot always pursue their ideas and a balance of guilt and initiative is necessary for a healthy ego.

Developing purpose in gifted students. To foster an identity as a successful producer or performer (Subotnik et al., 2011), preschoolers must be exposed to adult role models in the talent domain of interest. According to Erikson's theory, all culturally valued domains should be the stimuli for child's play, as this is when they test their understanding of varied aspects of an adult role. Preschoolers should be able to make choices, develop plans for action, solicit friends to participate in their fantasies, and be relatively free from foreign overcontrol. Some gifted children will have more intricate plans than their peers and may have difficulty communicating them or garnering support for play their peers cannot understand. The gifted child who is catered to at home must learn at school that others have initiative, as well. Relationships require negotiation and reciprocation. Teachers can ensure that all students have opportunities to experience the pursuit of their initiative and the pangs of guilt that come with overstepping. A favorable ratio should tend toward greater initiative, however, and schools should provide greater opportunity for all students to develop initiative than guilt.

Developing competence. Erikson was a firm believer that ego strength comes from a strong sense of identity and each crisis contributes to its construction. At school-age, children learn about the tools of their society, be they tangible or abstract. Productive adults use these tools and from about ages 6-12, children want to do or learn to do what adults do. Through practice and progress, they develop the essential strength of competence. During the crisis of Industry versus Inferiority, children hone their skills or learn to accept failure. If they are successful at the tasks they undertake, from schoolwork to sports, for example, they can believe 
in their ability to learn. This is a time when children learn to cooperate, but also to compare their abilities to those of others. If they find themselves wanting, it can lead to feelings of inferiority. Constantly working may lead to unhealthy beliefs about the importance of work. Always being successful may lead a child to fear failure or to have an unrealistic sense of one's abilities. Frequently being outperformed, on the other hand, can lead to a loss of motivation. Balance is key and opportunities for success and failure are important in achieving that balance. Being unchallenged will not lead to a sense of competence, a key point for those working with elementary-aged gifted children.

Developing competence in gifted students. During the elementary years, children are prepared to learn the tools of their culture. The maximal development of a talent requires that at this stage, children learn how to learn and how to do what is required for their talent domain. Belief in their competence must be strong in order for them to expend the effort and persist in later years when challenges become greater. Even when a domain's trajectory suggests a later beginning point (Subotnik et al., 2011), the resources for success in all domains commence in this stage. As they meet the crisis of industry versus inferiority, children must have opportunities to engage in realistic, authentic learning of culturally valued adult activities. They require feedback to see the progress of their learning and there should be some connection in what they do and what a productive adult does. The gifted child who is capable of comprehending and engaging in adult-level work must have opportunities to do so. Ego strength comes from real accomplishment. Erikson says, "Children cannot be fooled by empty praise and condescending encouragement. ... Their accruing ego identity gains real strength only from wholehearted and consistent recognition of real accomplishment, that is, achievement that has meaning in their culture." (1950/1980, p. 95). The budding talent should have real opportunities for advancement. 
Enrichment is a weak substitute for learning of actual adult productive activities (Cross \& Coleman, 2005).

On the opposite extreme of industry is inferiority. The highly capable student must have opportunities to experience feelings of inferiority in order to achieve a favorable ratio from this crisis. Risk-taking should be encouraged and all students should learn about the benefits of failure. This means that schools must offer actual challenges to their students, in the form of increasingly advanced learning opportunities. As a member of a school community, talented students should be aware of their impact on other students' favorable ratio. All students require opportunities for maximal learning. Identification for special services may be needed to ensure appropriate challenge, but care should be taken to maintain the social fabric of the class or school. All students are constructing their identities and all will benefit from curricula built on valued adult activities, which suggests a broadening of offerings in school.

Developing fidelity. The ultimate outcome of adolescence, Erikson (1961) proposed, is a sense of fidelity, an accurate, firmly held conviction of one's authentic, true self. Caught between ideology - what one "should" be, based on admired adult models - and what childhood experiences have led the adolescent to believe about what he or she $i s$, the crisis of adolescence is one of Identity versus Role Confusion. Ego strength depends on a firm sense of identity. Adolescents often find themselves in turmoil, not knowing to what lifestyle they should commit; trying on different personas or behaviors as they explore. Adolescence is a time of great physical change, which can put one's self-knowledge in a tailspin. Role confusion, which Erikson (1950/1980) later called identity diffusion, can lead to distress, in contrast with the comfort of an accomplished sense of ego identity, which Erikson describes as "the accrued confidence that the inner sameness and continuity prepared in the past are matched by the sameness and continuity 
of one's meaning for others" (1963, p. 261). The accrual of confidence happens with the development of hope, will, purpose, and skill in the years preceding adolescence.

Developing fidelity in gifted students. From grades 6 to 12, students should be coming to conclusions about who they are. The difficult middle-school years, with greater physiological diversity among students than at any other time, require sensitivity from educators. Erikson (1950/1963) points out that they are deeply concerned with who others think they are and how that jibes with their own self-perceptions. Highly talented students may reject that identity, preferring to blend in over standing out as exceptional (J. Cross, Bugaj, \& Mammadov, 2016; T. Cross, Coleman, \& Terhaar-Yonkers, 1991). If their early experiences have given them confidence in their initiative and competence, they will be more likely to pursue their identity in the talent domain. Identity explorations require opportunities to test themselves in various domains. Biographies of individuals who have been successful in a domain can be the impetus for an advanced reader to pursue talent development in that domain. Schools should provide adolescents with exceptional abilities many opportunities to test their interests in a psychosocially and physically safe environment.

In Erikson's time, a college undergraduate would likely have achieved an identity, but it is not necessarily the case in the $21^{\text {st }}$ century. Today's young adults may still need opportunities for identity exploration. Colleges interested in supporting the ego strength of students should be sensitive to the changing economic and cultural trends that may impact students' ability or desire to make commitments. For those who are ready, however, schools should provide opportunities to engage ever more deeply in their domain.

Developing love. As adolescents explore the many possible identities open to them in the crisis of the teenage years, they begin to enter into relationships. Before the crisis of Intimacy 
versus Isolation, the young adult has committed to a secure sense of self, but as social creatures, the time now comes to commit to others in a meaningful, lasting way. The strength of Love develops from experiences of sacrifice for another person, such as a romantic partner or close friend, or an institution, such as a club, a church, or a workplace.

Developing love in gifted students. Coleman (2012) writes of the passion gifted students may exhibit for a domain, making significant sacrifices as they pursue their interests. Such pursuits may indicate an early onset of the crisis of Intimacy versus Isolation, but perhaps could not culminate in the essential strength of Love until a stage of ascendancy similar to that of other young adults. This is an area ripe for research, with powerful implications for talent development. When young people have exceptional talents that can only be developed through significant sacrifices, what are the impacts on their psychosocial development? When schools offer opportunities to explore a domain in-depth, with such activities as clubs, competitions, field trips, and mentoring programs, gifted students can build a lasting relationship with their talent domain.

\section{Psychosocial Development and Talent Development}

The primary purpose in relating psychosocial development to talent development is to nurture the personal resources among those with potential so they will pursue opportunities and persist in learning until they have achieved at the highest level possible. For Subotnik et al. (2011), this means to achieve eminence in a talent domain. Whether seeking eminence or a less distinctive, but still exceptional level of achievement, students require ego strength. They must be hopeful that their environment will provide for them (hope), believe they can act on their own volition (will), recognize what is possible (purpose), have confidence in their abilities (competence), know who they are (fidelity), and be able to commit to others (love). For schools 
to effectively support these strengths, they must attend to aspects of the psychosocial arena in all areas, including curriculum development, teacher training, classroom management, school-wide policies, resource allocation, and so forth. A commitment to this approach will benefit all students, maximizing everyone's potential. Using Erikson's theory of psychosocial development as a foundation, this ambitious goal can be attained.

To begin, we must focus on the end. What does the identity of the young adult who has maximally developed his or her talent, look like? The identity of the individual must incorporate a belief in the self as a member of the culture of the domain of his or her talent (Oyserman, 2007). The accomplished violinist must see herself as a member of the music community, valuing the traditions and practices of that group. The budding athletic director will require a view of himself as a member of the sports community. The emerging scientific researcher must consider herself an academic and a scientist. Not only do these successful talents view themselves as members of their domain community, they must consider themselves successful in the activities of those domains. They are willing to put in the required hours of practice and know how to find resources for talent development. They are commited to their own success in the domain and are able to overcome challenges on the path of talent development. By engaging in activities such as those described above, schools can contribute to this ideal identity.

\section{Attending to Essential Strengths}

Although Erikson describes in detail the sequence of crises that occur as children mature, a paramount lesson of psychotherapy is that ego strength can be bolstered throughout life. The interactions of environment and individual continually influence thinking. For a school-based program to effectively build ego strength, it cannot focus solely on the crises that are in the stage of ascendancy. Support for identity formation should be a consideration at the earliest ages, even 
though the child will not face that crisis until adolescence. The strengths of hope and will, for example, have had their introduction before a child reaches preschool. Some children will have a favorable ratio of trust at school age, but others will not. Some children will have been given support for their autonomy, while others will have learned to be ashamed of their will to act and will doubt themselves, even to the point of helplessness. Psychotherapists work with adults to overcome these early deficiencies. With one eye on the adults their students will become and the other on the developments of childhood, educators, too, can create environments that support students' ego strengths at all ages. In fact, for a healthy society, it is necessary for schools to be supportive environments.

T. Cross, Cross, and Andersen (in press) proposed a school-based psychosocial curriculum model (SPCM) based on Erikson's theory. The SPCM emphasizes intra- and interpersonal understanding in the creation of activities that foster ego strength. Table 1, reprinted from T. Cross et al. (2016), describes possible activities and can be referenced as a stimulus for research, as well. As can be seen in Table 1, educators can create an environment that addresses the ends of the continuum Erikson describes for each crisis to support students in the development of essential strengths. For example, the ego strength of hope can be bolstered for students at any age by helping them recognize internal and external resources and by developing their strategies for self-soothing or help seeking.

As gifted students develop a sense of competence in the crisis of industry versus inferiority, teachers should be aware that gifted students often face the dilemma of outperforming their peers, leading to sensitivity to being the target of upward comparisons (STTUC; Exline \& Lobel, 1999). They should feel competent (intrapersonal) by being successful in challenging tasks put before them, but they will need strategies for dealing with peers who may be upset 
when they are outperformed (interpersonal). Teachers who wish to help their students develop the ego strength of competence will want to create an environment that considers both aspects of the crisis, avoiding high-stakes competition. To help students in their identity search, teachers can help them recognize the importance of staying authentic to themselves and their academic interests as they try on various possible selves. A next step in applying this framework for psychosocial development is to create classroom activities designed to support the essential strengths.

\section{Conclusion}

Our longstanding desire to create increasingly more effective approaches to teaching and learning have led us to the place where large numbers of studies have produced limited improvements. Lacking in these efforts have been theoretically consistent underpinnings guiding research and practice. The movement of the field of gifted education from an entity model of giftedness to one that emphasizes talent development has created opportunities to enhance our theories and practices by adding psychosocial training. To that end, applying Erikson's theory of psychosocial development as a framework for the development of talent among gifted students creates a consistent and powerful approach to maximizing the potential of students. It offers a model for development that attempts to establish essential strengths that will serve the person in numerous ways, enhancing their development of talents and their overall mental health. It provides a consistent, predictable theory that augments conceptions of giftedness that emphasize talent development, such as the school-based conception of giftedness and the mega-model of talent development. It provides the missing foundational link to augment our longstanding emphasis on pedagogy. 
The application of this adapted psychosocial theory creates the opportunity to more fully understand the complete teaching and learning enterprise by respecting the psychosocial development of students. In other words, the entire human is included in the learning process, not merely the intellectual side. Moreover, it creates myriad opportunities for research to enhance our level of sophistication in developing talent and maximizing student potential. 


\section{References}

Ambrose, D., VanTassel-Baska, J., Coleman, L. J., \& Cross, T. L. (2010). Unified, insular, firmly policed, or fractured, porous, contested, gifted education? Journal for the Education of the Gifted, 33, 453-478.

American Psychological Association. (2016). Understanding psychotherapy and how it works. Retrieved from http://www.apa.org/helpcenter/understanding-psychotherapy.aspx

Baumrind, D. (1966). Effects of authoritative parental control on child behavior. Child Development, 37, 887-907.

Baumrind, D. (1991). The influence of parenting style on adolescent competence and substance use. Journal of Early Adolescence, 11, 56-95.

Bloom, B. (Ed.). (1985). Developing talent in young people. New York, NY: Ballantine.

Burston, D. (2007). Erik Erikson and the American psyche: Ego, ethics, and evolution. Lanham, MD: Jason Aronson.

Coleman, L. J. (2012). Lived experience, mixed messages, and stigma. In T. L. Cross \& J. R. Cross (Eds.), Handbook for counselors serving students with gifts and talents (pp. 371391). Waco, TX: Prufrock Press.

Cross, J. R., Bugaj, S. J., \& Mammadov, S. (2016). Accepting a scholarly identity: Gifted students, academic crowd membership, and identification with school. Journal for the Education of the Gifted, 39, 23-48. DOI: 10.1177/0162353215624162

Cross, T. L., Cross, J., \& Spike, B. (2001, November). Publishing in the Gifted Child Quarterly. Presentation at the National Association for Gifted Children Convention, Cincinnati, OH.

Cross, J. R., Cross, T. L., \& Finch, W. H. (2010). Maximizing student potential versus building community: An exploration of right-wing authoritarianism, social dominance orientation, 
and preferred practice among supporters of gifted education. Roeper Review, 32, 235248.

Cross, T. L., Cross, J. R., \& Andersen, L. (in press). The School-Based Psychosocial Curriculum Model. In J. VanTassel-Baska \& C. A. Little (Eds.), Content-Based curriculum for highability learners ( $3^{\text {rd }}$ ed.). Waco, TX: Prufrock Press.

Cross, T. L., Coleman, L., \& Terhaar-Yonkers, M. (1991). The social cognition of gifted adolescents in schools: Managing the stigma of giftedness. Journal for the Education of the Gifted, 15, 44-55.

Erikson, E. H. (1963). Childhood and society (2 ${ }^{\text {nd }}$ ed.). New York, NY: W. W. Norton.

Erikson, E. H. (1950/1980). Growth and crises of the healthy personality. In E. H. Erikson, Identity and the life cycle (pp. 51-107). New York, NY: W. W. Norton.

Erikson, E. H. (1940/1987). Problems of infancy and early childhood. In S. Schlein (Ed.) A way of looking at things: Selected papers from 1930 to 1980 Erik H. Erikson (pp. 547-568). New York, NY: W. W. Norton.

Erikson, E. H. (1961). The roots of virtue. In J. S. Huxley (Ed.), The humanist frame. New York, NY: Harper \& Brothers.

Erikson, E. (1968). Identity: Youth and crisis. New York, NY: W. W. Norton.

Erikson, E. H. (1982). The life cycle completed: A review. New York, NY: W. W. Norton.

Exline, J. J., \& Lobel, M. (1999). The perils of outperformance: Sensitivity about being the target of a threatening upward comparison. Psychological Bulletin, 125, 307-337.

Gagné, F. (1995). From giftedness to talent: A developmental model and its impact on the language of the field. Roeper Review, 18, 103-111.

Gardner, H. (1983). Frames of mind: The theory of multiple intelligences. New York, NY: 


\section{BasicBooks.}

Gross, F. L. (1987). Introducing Erik Erikson. Lanham, MD: University Press of America. Hamlyn, S. (2007). An historical overview of psychotherapy. In C. Lister-Ford (Ed.), A short introduction to psychotherapy (pp. 3-31). Thousand Oaks, CA: Sage.

Hamre, B. K., \& Pianta, R. C. (2001). Early teacher-child relationships and the trajectory of children's school outcomes through eighth grade. Child Development, 72, 625-638.

Hobbes, R. (2007). Psychotherapy applications. In C. Lister-Ford (Ed.), A short introduction to psychotherapy (pp. 32-48). Thousand Oaks, CA: Sage.

Hull, J., \& Newport, M. (2011). Time in school: How does the US compare? Alexandria, VA: Center for Public Education. Retrieved from http://www.centerforpubliceducation.org/Main-Menu/Organizing-a-school/Time-inschool-How-does-the-US-compare

Marland, S. P., Jr. (1972). Education of the gifted and talented: Report to the Congress of the United States by the U.S. Commissioner of Education and background papers submitted to the U.S. Office of Education, 2 vols. Washington, DC: U.S. Government Printing Office. (Government Documents, Y4.L 11/2: G36)

Newman, B. M., \& Newman, P. R. (1995). Development through life: A psychosocial approach (6 $6^{\text {th }}$ ed.). Pacific Grove, CA: Brooks/Cole.

Oyserman, D. (2007). Social identity and self-regulation. In A. Kruglanski, \& T. Higgins (Eds.), Handbook of social psychology, $2^{\text {nd }}$ ed. (pp. 432-453). New York, NY: Guilford Press.

Renzulli, J. S. (1978). What makes giftedness: Reexamining a definition. The Phi Delta Kappan $60,160-184,261$.

Roazen, P. (1976). Erik H. Erikson: The power and limits of a vision. New York, NY: Free Press. 
Stefanou, C. R., Perencevich, K. C., DiCintio, M., \& Turner, J. C. (2004). Supporting autonomy in the classroom: Ways teachers encourage student decision making and ownership. Educational Psychologist, 39, 97-110.

Sternberg, R. J. (1986). A triarchic theory of intellectual giftedness. In R. J. Sternberg \& J. E. Davidson (Eds.), Conceptions of giftedness (pp. 223-243). Cambridge, UK: Cambridge University Press. 
Table 1

Possible lessons from issues and themes suggested by Erikson's psychosocial crises

\begin{tabular}{|c|c|c|c|}
\hline $\begin{array}{l}\text { Essential } \\
\text { Strength }\end{array}$ & $\begin{array}{c}\text { Crisis - Positive } \\
\text { (Intrapersonal) }\end{array}$ & $\begin{array}{c}\text { Crisis - Negative } \\
\text { (Interpersonal) }\end{array}$ & $\begin{array}{l}\text { Approximate } \\
\text { Age of Initial } \\
\text { Crisis } \\
\end{array}$ \\
\hline \multirow[t]{4}{*}{ Hope } & Trust & Mistrust & Birth to 1 year \\
\hline & Identify internal resources & $\begin{array}{l}\text { Identify resources and } \\
\text { barriers (e.g., supporters and } \\
\text { nonsupporters) }\end{array}$ & \\
\hline & Self-soothing & Counseling & \\
\hline & Self-talk & Counseling & \\
\hline \multirow[t]{3}{*}{ Willpower } & Autonomy & Shame and Doubt & 1 to 3 years \\
\hline & Persistence & Letting go & \\
\hline & $\begin{array}{l}\text { Creative ways to pursue } \\
\text { desires }\end{array}$ & Recognizing impact on others & \\
\hline \multirow[t]{13}{*}{ Purpose } & Initiative & Guilt & 3 to 6 years \\
\hline & Goal setting & Realistic goal setting & \\
\hline & Goal orientation (mastery) & $\begin{array}{l}\text { Goal orientation } \\
\text { (performance) }\end{array}$ & \\
\hline & Flexibility & $\begin{array}{l}\text { Resilience (when unable to } \\
\text { act) }\end{array}$ & \\
\hline & Self-advocacy & Avoiding narcissism, egotism & \\
\hline & Acting independently & Building relationships & \\
\hline & Being yourself & Considering others & \\
\hline & Developing passion & Developing balance & \\
\hline & Doing your best & Prosocial behavior & \\
\hline & $\begin{array}{l}\text { Pursuit of individual } \\
\text { needs/desires }\end{array}$ & $\begin{array}{l}\text { Pursuits to benefit the } \\
\text { common good }\end{array}$ & \\
\hline & Working alone & $\begin{array}{l}\text { Cooperation/working in } \\
\text { groups }\end{array}$ & \\
\hline & Positive striving & $\begin{array}{l}\text { Evaluative concerns } \\
\text { (perfectionism) }\end{array}$ & \\
\hline & Avoiding boredom & Waiting & \\
\hline \multirow[t]{4}{*}{ Competence } & Industry & Inferiority & 6 to 12 years \\
\hline & $\begin{array}{l}\text { Motivation }\left(\mathrm{V}^{*} \mathrm{E}\right) \\
\text { Recognizing value and } \\
\text { expectation of success } \\
\text { (self-efficacy) }\end{array}$ & $\begin{array}{l}\text { Doing in order to develop } \\
\text { intrinsic motivation }\end{array}$ & \\
\hline & $\begin{array}{l}\text { Motivation (SDT) } \\
\text { Recognizing autonomy, } \\
\text { competence, relatedness } \\
\text { needs }\end{array}$ & $\begin{array}{l}\text { Recognizing healthy balance } \\
\text { in self-determination needs }\end{array}$ & \\
\hline & Identifying interests & Trying new things & \\
\hline
\end{tabular}




\begin{tabular}{|c|c|c|c|}
\hline & Your social goals & Others' social goals & \\
\hline & Succeeding & Failing (positive) & \\
\hline & Outperforming others & STTUC & \\
\hline & Self-advocacy & Supporting others' success & \\
\hline & $\begin{array}{l}\text { Accepting/pursuing } \\
\text { challenge }\end{array}$ & BFLPE & \\
\hline & Self-esteem & Social comparison & \\
\hline & Practice & Entity beliefs & \\
\hline \multirow[t]{9}{*}{ Fidelity } & Identity & Role Confusion & 12 to 20 years \\
\hline & $\begin{array}{l}\text { Knowing } \\
\text { own/family/community } \\
\text { values }\end{array}$ & Learning about others' values & \\
\hline & $\begin{array}{l}\text { Understanding own } \\
\text { abilities }\end{array}$ & $\begin{array}{l}\text { Recognizing limitations in } \\
\text { abilities (social comparison) }\end{array}$ & \\
\hline & Career development & Multipotentiality & \\
\hline & Foreclosure & Moratorium, experimentation & \\
\hline & Authenticity & $\begin{array}{l}\text { Possible selves (Effect on } \\
\text { competence when trying on } \\
\text { other selves) }\end{array}$ & \\
\hline & Crowd membership & $\begin{array}{l}\text { Changing or multiple } \\
\text { memberships }\end{array}$ & \\
\hline & Self-concept & Reputation & \\
\hline & Being yourself & $\begin{array}{l}\text { Information Management } \\
\text { Model (e.g., code-switching) }\end{array}$ & \\
\hline \multirow[t]{4}{*}{ Love } & Intimacy & Isolation & 20 to 40 years \\
\hline & $\begin{array}{l}\text { Identifying opportunities } \\
\text { commensurate with one's } \\
\text { values }\end{array}$ & $\begin{array}{l}\text { Learning the requirements of } \\
\text { one's role in a group }\end{array}$ & \\
\hline & Leadership training & Servant leadership & \\
\hline & $\begin{array}{l}\text { Features of positive } \\
\text { romantic relationships }\end{array}$ & $\begin{array}{l}\text { Features of negative romantic } \\
\text { relationships }\end{array}$ & \\
\hline
\end{tabular}

Reprinted from T. Cross, Cross, \& Andersen, in press. 